\title{
Casca do fruto da mamoneira como substrato para as plantas ${ }^{1}$
}

\author{
Guilherme E. Machado Lopes ${ }^{2}$, Henrique Duarte Vieira ${ }^{3}$, Janie Mendes Jasmim ${ }^{3}$, Aldo Shimoya 4 , \\ Cláudio Roberto Marciano 5
}

\section{RESUMO}

A casca do fruto da mamoneira (CFM) é um resíduo gerado, em grande quantidade, no beneficiamento da mamona. O objetivo desta pesquisa foi avaliar as características físicas e químicas da CFM e seu efeito, como substrato, para plantas. A avaliação das características da CFM foi realizada em um experimento fatorial (2x3), constituído da combinação de dois tipos de casca (CFM in natura e compostada) e três granulometrias (peneiras 3, 5 e $10 \mathrm{~mm}$ de malha), em delineamento de blocos ao acaso. Os teores de macro e micronutrientes, condutividade elétrica (CE), pH, densidade seca (DS), densidade úmida (DU), porosidade total (PT) e espaço de aeração (EA) foram avaliados. A avaliação da CFM como substrato para plantas foi realizada, utilizando-se mudas de tomateiro (Lycopersicon esculentum Mill.) e estacas de pingo-de-ouro (Duranta repens L.) como espécies indicadoras. Para o cultivo de mudas de tomateiro, a CFM, na granulometria de $3 \mathrm{~mm}$, in natura, ou compostada, foi misturada com Plantmax ${ }^{\circledR}$ em cinco proporções [0:100; 25:75; 50:50; 75:25; 100:0 (v/v)]. Para o enraizamento de pingo-de-ouro, estacas foram plantadas em CFM, in natura, ou compostada, de três granulometrias (3,5 e $10 \mathrm{~mm})$. A CFM compostada, na granulometria de $3 \mathrm{~mm}$, apresentou as características físicas mais adequadas. A CFM in natura apresentou efeitos negativos, sendo inadequada como substrato. A CFM compostada permitiu obter $100 \%$ de germinação e mudas normais de tomateiro, bem como estacas enraizadas de pingo- de- ouro, podendo, portanto, ser utilizada como substrato, pura, ou em misturas.

Palavras-chave: mamona, resíduo, características físicas.

\begin{abstract}
\section{Castor bean husk as substrate for plants}

Castor bean husk $(\mathrm{CBH})$ is a residue generated in large amounts in the castor bean processing. The aim of this study was to evaluate the chemical and physical characteristics of $\mathrm{CBH}$ and its effect used as substrate for plants. $\mathrm{CBH}$ characteristics were evaluated in a (2x3) factorial randomized block design, consisting of a combination of two husk types (CBH fresh and composted) and three grades (mesh $3 \mathrm{~mm}, 5 \mathrm{~mm}$ e $10 \mathrm{~mm}$ ). Macro and micronutrient contents, $\mathrm{pH}$, electrical conductivity, wet density, dry density, total porosity and air space were evaluated. The evaluation of $\mathrm{CBH}$ as substrate for plant growth was carried out using tomato (Lycopersicon esculentum Mill.) seedlings and golden dew drop (Duranta repens L.) cuttings as indicator species. Tomato seedlings were grown on CBH 3 mm grade, fresh or composted, mixed to Plantmax ${ }^{\circledR}$ in five ratios $[0: 100 ; 25: 75 ; 50: 50 ; 75: 25 ; 100: 0(\mathrm{v} / \mathrm{v})]$. Rooting of golden dew drop cuttings was carried out on $\mathrm{CBH}$, fresh or composted, using three grades $(3,5$ and $10 \mathrm{~mm})$. The composted $3 \mathrm{~mm}$ grade

\footnotetext{
Recebido para publicação em junho de 2010 e aprovado em março de 2011

${ }^{1}$ Retirado da tese do primeiro autor.

${ }^{2}$ Engenheiro-Agrônomo, Doutor. Produção Vegetal, Petrobras Biocombustível. Av Presidente Vargas, 3131, 9º andar, sala 902, $20210-030$ Cidade Nova, Rio de Janeiro, Brasil gemlopes@gmail.com.br.

${ }^{3}$ Engenheiros-Agrônomos, Doutores. Universidade Estadual do Norte Fluminense, Produção Vegetal. Av Alberto Lamego, 2000 Parque Califórnia, $28013-602$ Campos dos Goytacazes, RJ, Brasil. henrique@uenf.br, janie@uenf.br.

${ }^{4}$ Engenheiro-Agrônomo, Doutor. Universidade Salgado de Oliveira, Produção Vegetal. Avenida Osvaldo Cardoso de Melo, 856, Parque Dom Bosco, 28030-112 Campos dos Goytacazes, RJ, Brasil. aldoshimoya@yahoo.com.br

${ }^{5}$ Engenheiro-Agrônomo, Doutor. Universidade Estadual do Norte Fluminense, Solos e Nutrição de Plantas. Av. Alberto Lamego, 2000 Parque Califórnia, 28013-602, Campos dos Goytacazes, RJ, Brasil. marciano@uenf.br.
}

Rev. Ceres, Viçosa, v. 58, n.3, p. 350-358, mai/jun, 2011 
CFM showed the most suitable physical characteristics. The fresh $\mathrm{CBH}$ had negative effects both on seedling growth and rooting of cuttings, proving unsuitable as substrate. Composted $\mathrm{CBH}$ allowed for $100 \%$ of germination and normal tomato seedlings, as well as rooted golden dew drop cuttings, therefore it can be used as substrate, alone or in mixtures.

Key words: Castor bean, physical properties, residues.

\section{INTRODUÇÃO}

No Brasil, há um aumento na demanda de produção de plantas em recipientes e substratos ecologicamente corretos. O desenvolvimento de substratos vegetais, para propagação e,ou, para o cultivo, nas diferentes regiões do Brasil, depende, dentre outros fatores, da disponibilidade de matérias primas abundantes e baratas, com potencial de utilização como substrato para plantas (Andriolo et al., 1999). Neste sentido, os resíduos da agroindústria, como a fibra de coco e outros materiais orgânicos, como a casca do fruto da mamoneira, aparecem como alternativas promissoras, pois estão facilmente disponíveis e são, em geral, baratos.

A casca de fruto de mamoneira é um material que, atualmente, é descartado ou, utilizado como adubo ou combustível na geração de calor. Para cada tonelada de semente de mamona processada, são gerados cerca de $620 \mathrm{~kg}$ de casca (Severino et al., 2005). Estima-se que, somente em 2005, foram gerados no Brasil, aproximadamente, 130.000 toneladas de casca de frutos de mamona, provenientes do beneficiamento dessa oleaginosa (Lima et al., 2008).

A utilização de resíduos agroindustriais como substratos contribui para a redução de custos de produção e para o aproveitamento de resíduos cujo descarte no ambiente representa grande impacto negativo. Entretanto, a sua utilização como substrato para o cultivo de plantas pode envolver problemas de fitotoxidez, salinidade, desordens nutricionais e,ou, alterações metabólicas (enzimáticas ou hormonais) (Ortega et al., 1996). Alguns desses problemas podem ser minimizados e,ou, eliminados pela compostagem (Yates \& Rogers, 1981) ou por simples lavagem do material (Carrijo et al., 2002). Além disso, é importante conhecer as propriedades físicas e químicas dos componentes que serão empregados no preparo do substrato (Kämpf, 2000b)

Segundo Handreck (1993), os problemas de salinidade e a presença de substâncias tóxicas são facilmente detectáveis, durante os estádios iniciais do desenvolvimento vegetal, uma vez que, de maneira geral, a germinação de sementes e o enraizamento de estacas são mais facilmente e severamente danificados do que plantas adultas.
Para caracterizar fisicamente um material para uso como substrato, considera-se, normalmente, a densidade, porosidade, espaço de aeração e os volumes de água disponíveis em diferentes potenciais (Schmitz et al., 2002). A grande diversidade de matérias primas utilizadas na composição de substratos também resulta em diferentes características químicas. As características químicas e físico-químicas, normalmente, determinadas em substratos são o pH, a condutividade elétrica (CE), e os teores de macro e micronutrientes (Abreu et al., 2002; Schmitz et al., 2002).

Objetivou-se, com este trabalho, avaliar as características químicas e físicas da casca do fruto da mamoneira e sua utilização como substrato, puro ou em mistura, utilizando-se mudas de tomateiro (Lycopersicon esculentum) e estacas de pingo-de-ouro (Duranta repens) como espécies indicadoras.

\section{MATERIAL E MÉTODOS}

A casca de fruto da mamoneira (CFM) foi obtida após o descascamento mecânico.

Parte da casca foi submetida à decomposição aeróbica, por cerca de 180 dias (novembro/2006 a abril/2007), a céu aberto. Durante esse período, foram monitoradas, periodicamente, a umidade, a aeração e a temperatura do material, seguindo as recomendações de Kiehl (1985). Quando foi observado decréscimo e estabilidade térmica, o que ocorreu por volta dos 180 dias, o material foi considerado compostado. Amostras do material, in natura e decomposto, foram encaminhadas para análise química de resíduo (macro e micronutrientes) no laboratório de análise da UFRRJ. As CFM in natura e compostada foram trituradas em moinho triturador marca Nogueira, modelo DPM 500, em três granulometrias: peneiras 3 mm, 5 mm e $10 \mathrm{~mm}$. Amostras de CFM in natura e compostada nas três granulometrias foram encaminhadas para o Laboratório de Análise de Substrato da Escola de Agronomia da UFRGS. Foram realizadas as análises de $\mathrm{pH}$ em água $(\mathrm{pH})$; condutividade elétrica (CE), em dS m $\mathrm{m}^{-1}$ e análises de caracterização física: densidade úmida (DU), em $\mathrm{kg} \mathrm{m}^{-3}$; densidade seca (DS), em $\mathrm{kg} \mathrm{m}^{-3}$; porosidade total (PT), em $\mathrm{em}^{3} \mathrm{~m}^{-3}$ e espaço de aeração (EA), em $\mathrm{m}^{3} \mathrm{~m}^{-3}$. 
O delineamento experimental utilizado foi em blocos ao acaso, com seis tratamentos e três repetições. Os tratamentos originaram-se de um fatorial $2 \times 3$, proveniente da combinação dos fatores: casca de fruto da mamoneira in natura e compostada e três granulometrias (peneiras 3, 5 e $10 \mathrm{~mm}$ ).

Os dados foram submetidos à análise de variância e as médias comparadas, pelo teste de Tukey a 5\% de probabilidade. As análises estatísticas foram realizadas, utilizando-se os procedimentos do programa Genes (Cruz, 2006).

Para avaliar o uso da CFM como substratos para plantas, foram realizados dois experimentos em casa de vegetação, na Estação Experimental de Itaocara da PESAGRORIO, utilizando-se o tomateiro (Lycopersicon esculentum) e estacas de pingo-de-ouro (Duranta repens) como plantas indicadoras.

No experimento com mudas de tomateiro, os tratamentos consistiram em uma combinação fatorial $2 \times 5$, sendo dois tipos de CFM, in natura e compostada, na granulometria $3 \mathrm{~mm}$, que apresentaram os melhores resultados na avaliação das características físicas, e cinco percentuais de mistura com o substrato comercial Plantmax $^{\circledast}(0: 100 ; 25: 75 ; 50: 50 ; 75: 25 ; 100: 0(\mathrm{v} / \mathrm{v})$. ACFM foi obtida como descrito anteriormente. Foram utilizadas sementes de tomate cultivar, Santa Cruz, Kada Gigante, semeadas em bandejas de poliestireno expandido de 128 células (capacidade de $40 \mathrm{~cm}^{3} /$ célula). Após a emergência, efetuou-se o desbaste, de modo a manter uma planta por célula. Foi utilizado o delineamento experimental em blocos casualizados, com quatro repetições, sendo cada unidade experimental constituída por 32 células, com 12 células na parcela útil. Ao final do período experimental de 30 dias, foram avaliadas: a) germinação (GER); b) altura de planta (AP); c) diâmetro do caule (tomate); d) comprimento de raízes primárias (CRP); e) massa de matéria fresca da parte aérea (MFPA); f) massa de matéria fresca do sistema radicular (MFSR); g) massa de matéria seca da parte aérea (MSPA) e h) massa de matéria seca do sistema radicular (MSSR).

No experimento de enraizamento, foram utilizadas estacas semilenhosas da espécie ornamental pingo-de-ouro com cerca de $10 \mathrm{~cm}$ de comprimento, com três gemas e um par de folhas. Os tratamentos consistiram em CFM, in natura e compostada, em três granulometrias (peneiras 3 , 5 e $10 \mathrm{~mm}$ ) e um tratamento com vermiculita, substrato utilizado no enraizamento de estacas de inúmeras espécies vegetais. Foi utilizado o delineamento experimental em blocos ao acaso, com quatro repetições, sendo cada unidade experimental constituída por 32 estacas, com 12 estacas por parcela útil, inseridas no substrato, em bandejas de poliestireno expandido de 128 células (capacidade de $40 \mathrm{~cm}^{3} /$ célula),
As bandejas foram mantidas sob nebulização intermitente, por um período de 12 horas diárias, de 7 às 19 horas, sendo o tempo de nebulização de 30 segundos, a cada 10 minutos, controlados por temporizador, durante 30 dias. Após esse período, as 12 estacas da parcela útil foram avaliadas quanto: a) percentual de enraizamento (ENRZ); b) percentual de sobrevivência das estacas (ESBR); c) número de raízes primárias (NRP); d) comprimento de raízes primárias (CRP); e) massa de matéria fresca da parte aérea (MFPA); f) massa de matéria fresca do sistema radicular (MFSR); g) massa de matéria seca da parte aérea (MSPA) e h) massa de matéria seca do sistema radicular (MSSR).

Os dados obtidos nos dois experimentos foram submetidos à análise de variância e, as médias, comparadas pelo teste de Tukey a 5\% de probabilidade, e à análise de regressão polinomial para as características quantitativas, utilizando-se os procedimentos do programa Genes (Cruz, 2006).

\section{RESULTADOS E DISCUSSÃO}

As concentrações de nutrientes totais da casca do fruto da mamoneira (CFM), in natura e compostada, estão na Tabela 1. Com a decomposição aeróbica, ocorreu redução da relação C/N (de 17,4 para 13,5) da CFM. Durante o processo de compostagem de casca de eucalipto, também foi observada a redução da relação $\mathrm{C} / \mathrm{N}$ do material, de 69 para 22 (Hardy \& Sivasithamparam, 1989). A relação $\mathrm{C} / \mathrm{N}$ de resíduo da indústria de chá preto também foi reduzida de 20,1 para 12,1 após decomposição aeróbica (Lima et al., 2007). Os valores de relação C/N observados para a CFM, compostada ou não, estão um pouco abaixo daqueles citados, por Hartmann et al. (1997), como recomendáveis (relação $\mathrm{C} / \mathrm{N}$ em torno de 20 ). No entanto, valores altos de relação $\mathrm{C} / \mathrm{N}$, acima de 20 ou mais, podem causar excessiva redução de volume e imobilização de nitrogênio, durante a sua utilização, o que pode inviabilizar o uso de materiais com essas características.

Houve redução nos teores de $\mathrm{K}, \mathrm{Cl}$ e $\mathrm{Na}$ (Tabela 1), decorrente, possivelmente, da forma de decomposição a céu aberto e da lixiviação desses elementos pela água da chuva, uma vez que a disponibilização do $\mathrm{K}$ nos restos culturais pode ser rápida, e, esse elemento, intensamente lixiviado, dependendo da quantidade de chuva, com pequena dependência dos processos microbianos (Giacomini et al., 2003; Rosolem, 2006). Redução nos teores de Na e K também foram observados por Hardy \& Sivasithamparam (1989), durante o processo de compostagem de casca de eucalipto.

Observaram-se, ainda, teores mais baixos de $\mathrm{S}, \mathrm{C}$ e B e o aumento dos teores de $\mathrm{N}(20 \%), \mathrm{P}(33 \%), \mathrm{Ca}(126 \%)$, $\mathrm{Mg}(45 \%), \mathrm{Fe}(148,6 \%), \mathrm{Cu}(300 \%), \mathrm{Zn}(237,5 \%)$ e $\mathrm{Mn}$ $(165,5 \%)$. Resultados semelhantes foram relatados por 
Hardy \& Sivasithamparam (1989) que observaram aumento nos teores de N, P, Ca, Fe, $\mathrm{Cu}$ e $\mathrm{Mn}$, ao analisarem os efeitos da compostagem sobre algumas características químicas de casca de eucalipto. Esses resultados, possivelmente, devem-se à mineralização do material resultante da atividade microbiológica, durante o processo de decomposição aeróbica.

A CFM decomposta apresentou melhores resultados que a CFM in natura, em todas as granulometrias, sendo melhores os observados quando usada a granulometria de $3 \mathrm{~mm}$, exceto para as características DU, PT e EA cujos resultados não diferiram daqueles observados para a CFM, decomposta, na granulometria de $5 \mathrm{~mm}$, e pH, cujo valor foi mais elevado do que os observados nas demais granulometrias, que também diferiram entre si. A CFM com granulometria de $10 \mathrm{~mm}$ foi a que apresentou as piores características, tanto para in natura como decomposta, exceto quanto ao $\mathrm{pH}$ que foi mais baixo e mais próximo à faixa descrita na literatura como adequada para substratos (5,0 a 5,8) (Kämpf, 2000b).

A CFM in natura apresentou altos valores de salinidade (Tabela 2), expressa pela condutividade elétrica (CE) de 3,2 dS m-1. Após a decomposição, a redução nos teores de $\mathrm{K}, \mathrm{Cl}$ e $\mathrm{Na}$ contribuiu para a redução da $\mathrm{CE}$, que apresentou valor médio de $0,61 \mathrm{dS} \mathrm{m}^{-1}$. Hardy \& Sivasithamparam (1989) também observaram redução significativa da CE, após a compostagem de casca de eucalipto. A CE aumentou de forma significativa com a redução da granulometria na CFM in natura, o que parece estar relacionado com a maior área superficial disponível às reações de troca das partículas menores. Considerando os valores de CE propostos por Cavins et al (2000), de 0,26 a $0,75 \mathrm{mS} \mathrm{cm}^{-1}$ como adequados, após a decomposição aeróbica do material, os valores de CE, elevados na CFM in natura, em todas as granulometrias analisadas, foram reduzidos para níveis considerados baixos e adequados ao cultivo de espécies sensíveis.. Este foi um importante efeito benéfico da compostagem, visto que a CE alta pode inviabilizar o cultivo, por causa do aumento do potencial osmótico da solução do substrato, que afeta a absorção de água e nutrientes pela planta.
$\mathrm{O}$ pH ideal, para substratos com predominância de matéria orgânica, encontra-se na faixa de 5,0 a 5,8 (Kämpf, 2000b). Os valores de $\mathrm{pH}$ que mais se aproximaram desta faixa foram observados na CFM in natura, nas granulometrias de 5 e $10 \mathrm{~mm}$. Houve aumento significativo do $\mathrm{pH}$, com a decomposição aeróbica e com a redução da granulometria, mas os valores do $\mathrm{pH}$ da CFM compostada nas três granulometrias estão acima da faixa considerada ideal, (Tabela 2), o que pode acarretar problemas com a disponibilidade de $\mathrm{P}$ e de micronutrientes, como Fe, $\mathrm{Mn}$, Zn e Cu (Kämpf, 2000b). O aumento do pH, com o processo de compostagem, também foi registrado para outros materiais orgânicos (Hardy \& Sivasithamparam, 1989; Lima et al., 2007).

O valor de densidade seca (DS), considerado ideal para substrato hortícola, situa-se entre $400-500 \mathrm{~kg} \mathrm{~m}^{-3}$ (Schmitz et al., 2002). Tanto a CFM in natura como a compostada apresentaram DS abaixo desta faixa, embora tenha havido um aumento significativo da densidade, com a decomposição e a redução da granulometria (Tabela 2). Os valores de DS observados para o material decomposto encontram-se na faixa de $200-400 \mathrm{~kg} \mathrm{~m}^{-3}$, considerada aceitável para cultivo em vasos de até $15 \mathrm{~cm}$ de altura (Kämpf, 2000 b). Esses valores, inferiores a $400-500 \mathrm{~kg} \mathrm{~m}^{-3}$, poderiam ocasionar problemas para a drenagem do substrato, se utilizado puro ou em percentuais elevados, em misturas, para o cultivo de plantas em recipientes com maior altura.

Para a característica porosidade total (PT), o valor considerado ideal é de $0,85 \mathrm{~m}^{3} \mathrm{~m}^{-3}$ para substratos hortícolas (De Boodt \& Verdonck, 1972; Schmitz et al., 2002). Verificou-se que a PT da CFM aumentou, de forma significativa, com o processo de decomposição e com a redução da granulometria, aproximando-se do valor ideal nas granulometrias $3 \mathrm{~mm}\left(0,82 \mathrm{~m}^{3} \mathrm{~m}^{-3}\right)$ e $5 \mathrm{~mm}\left(0,80 \mathrm{~m}^{3} \mathrm{~m}^{-3}\right)$ (Tabela 2). A redução da PT, com o aumento da granulometria, parece contraditória, entretanto, esse efeito pode ser explicado com base nos relatos de Fermino (2002), em que, em materiais com partículas maiores, caso do material com granulometria de $10 \mathrm{~mm}$, ocorre uma combinação de partículas de tamanhos diferentes, pois partí-

Tabela 1. Teores de macro e micronutrientes de casca de fruto de mamoneira (CFM) in natura e após decomposição aeróbica por 180 dias

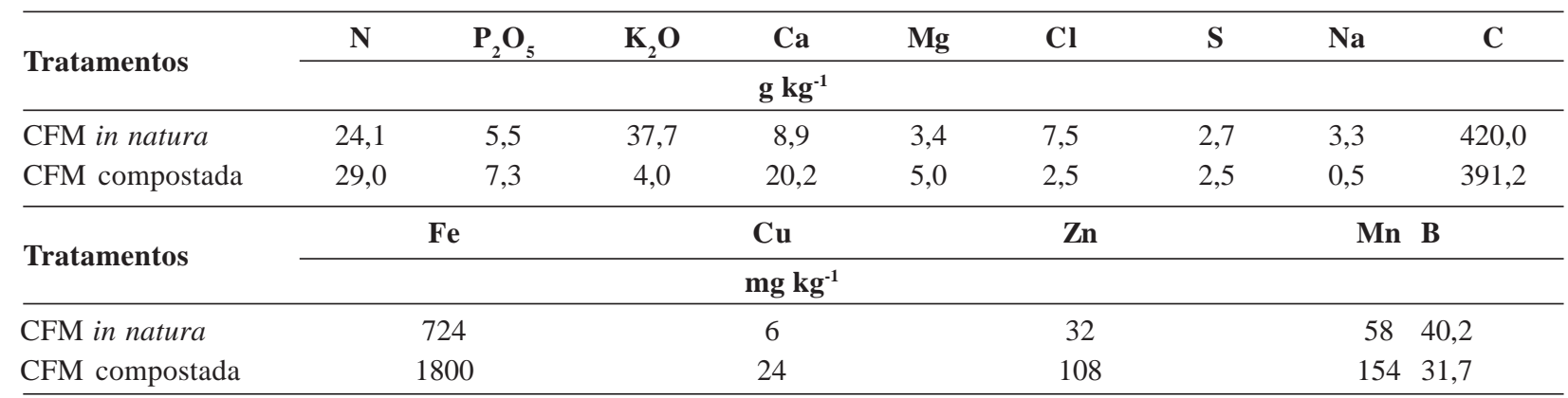




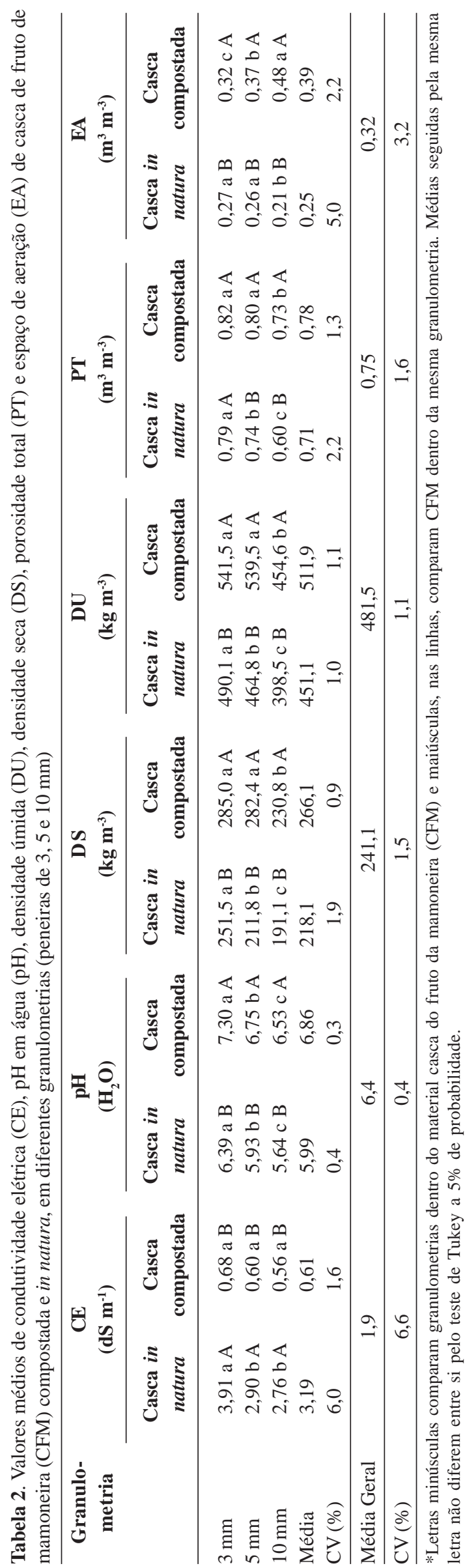

culas menores alojam-se entre os espaços livres formados pelo arranjo das partículas maiores.

O valor considerado ideal para o espaço de aeração (EA) de substratos hortícolas é de $0,30 \mathrm{~m}^{3} \mathrm{~m}^{-3}$ (Schmitz et al., 2002). A CFM in natura, nas três granulometrias, apresentou valor de EA inferior ao ideal. Entretanto, a decomposição elevou esse valor de forma significativa, sendo que o valor obtido com a granulometria de $3 \mathrm{~mm}$ ficou bem próximo ao ideal $\left(0,32 \mathrm{~m}^{3} \mathrm{~m}^{-3}\right)$, enquanto com as granulometrias de $5 \mathrm{~mm}$ e $10 \mathrm{~mm}$ os EA foram elevados, entre $0,37 \mathrm{e} 0,48 \mathrm{~m}^{3} \mathrm{~m}^{-3}$, respectivamente (Tabela 2). Materiais com espaço de aeração acima do ideal, como o detectado com as granulometrias de 5 e $10 \mathrm{~mm}$, podem resultar em deficiência hídrica às plantas, principalmente no caso de irrigações pouco frequentes, mas podem ser utilizados como condicionadores de substratos (Schmitz et al., 2002). Por outro lado, materiais com EA abaixo da faixa ideal dificultam as trocas gasosas nas raízes e prejudicam o desenvolvimento da planta.

De modo geral, observou-se que a decomposição aeróbica contribuiu para a melhoria das características físicas e químicas para uso da CFM como substrato. O material com granulometria de $3 \mathrm{~mm}$ apresentou características físicas mais adequadas. Assim, para melhor avaliação, foi estudado o efeito dos materiais, como componentes de substrato, utilizando-os na germinação e no crescimento de mudas de tomateiro e no enraizamento de estacas de pingo-de-ouro.

Entre as características avaliadas nas mudas de tomateiro, AP, DC, MFPA, NSPA e MSSR apresentaram diferenças significativas entre os tratamentos $(\mathrm{P}<0,05)$, para os efeitos simples, dos fatores tipo de CFM e mistura, e para a interação dos fatores tipo de CFM x mistura. As características CRP e MFSR somente apresentaram diferenças significativas para o efeito mistura para a CFM in natura.

Embora a germinação do tomateiro tenha sido de 100 $\%$ em todos os tratamentos em que se utilizou a CFM in natura, não havendo diferença entre eles, a CFM in natura prejudicou o crescimento das mudas dessa espécie. Por outro lado, quando se utilizou a CFM compostada, não foram observados os mesmos efeitos negativos (Figura 1).

Os efeitos fitotóxicos às mudas de tomateiro, encontrados na CFM in natura, possivelmente estão relacionados com a alta condutividade elétrica (CE) desse material, de $3,91 \mathrm{dS} \mathrm{m}^{-1}$ (Tabela 2) para a granulometria de $3 \mathrm{~mm}$, encontrada nas análises de caracterização química, o que pode reduzir o vigor e o crescimento das plantas. Esta alta $\mathrm{CE}$ pode ser decorrente dos altos teores de $\mathrm{Cl}, \mathrm{K}$ e $\mathrm{Na}$, encontrados no material (Tabela 1). Muitos resíduos agrícolas e da agroindústria apresentaram limitação ao crescimento vegetal, decorrente da alta $\mathrm{CE}$, conforme constata- 
do nos resíduos de sisal (Lacerda et al., 2006) e da indústria de couro (Daudt et al., 2007), muito embora a sensibilidade das plantas à CE do substrato seja variável, segundo a espécie e a idade da planta (Kämpf, 2000a), o que foi constatado durante o cultivo de bromeliáceas em substrato composto por casca de coco (Jasmim et al., 2006). Além disso, é possível a presença de substâncias orgânicas em níveis fitotóxicos no material CFM in natura que, embora não tenham sido objeto de análise neste trabalho, foram detectadas em cascas de diferentes espécies florestais (Still et al., 1976; Ortega et al., 1996) e em bagaço de oliva (Estaún et al., 1985), com influência negativa na germinação e no desenvolvimento vegetal.

A redução do percentual de CFM in natura na mistura de Plantmax ${ }^{\circledR}$ aumentou, significativamente, os valores de DC e CRP das mudas de tomateiro. A presença da CFM in natura na mistura, mesmo nos percentuais mais baixos, continuou inibindo, significativamente, o crescimento das mudas de tomateiro, como indicam as outras variáveis de crescimento da parte aérea (AP, MFPA e MSPA) e do sistema radicular (MFSR e MSSR), comparativamente aos resultados obtidos com o tratamento com Plantmax ${ }^{\circledR}$ puro (Figura 1).

Por outro lado, quando se utilizou a CFM compostada, pura ou em mistura, não foram observados efeitos negativos sobre as características estudadas, nos níveis daqueles provocados pelo uso da CFM in natura. Após o processo de decomposição aeróbica, a condutividade elétrica da CFM, na granulometria de $3 \mathrm{~mm}$, foi reduzida para $0,68 \mathrm{dS} \mathrm{m}^{-1}$, considerada adequada ao crescimento vegetal, segundo Cavins et al. (2000), o que contribuiu para os bons resultados encontrados. Também foram observados teores mais baixos de $\mathrm{Cl}$, $\mathrm{K}$ e Na (Tabela 1) cujas reduções podem ter contribuído para o valor mais baixo de CE. Além disso, há a hipótese de que substâncias orgânicas, possivelmente presentes em níveis fitotóxicos na CFM in natura, possam ter sido inativadas ou reduzidas a níveis não tóxicos, durante o processo de decomposição aeróbica a que foi submetido o material. Em outros materiais vegetais utilizados como substrato vários autores relatam a redução nos níveis de compostos orgânicos considerados fitotóxicos após o processo de compostagem (Yates \& Rogers 1981; Estaún et al., 1985; Hardy \& Sivasithamparam, 1989).

As diferentes misturas de CFM compostada e Plantmax ${ }^{\circledR}$ não influenciaram a germinação do tomateiro que atingiu $100 \%$ em todos os tratamentos. As variáveis CRP e MFSR não diferiram, estatisticamente, entre os tratamentos. As variáveis AP, DC e MSSR apresentaram efeito quadrático, e, as variáveis MFPA e MSPA, efeito linear crescente, à medida que se aumentou o percentual de CFM no substrato, resultado, possivelmente, relacionado com as melhores condições físicas do substrato, principalmen- te, maior porosidade e melhor aeração, proporcionadas pela CFM, evidenciado pelo maior desenvolvimento do sistema radicular.

Resultados semelhantes foram relatados por Gruszynski (2002), que, ao avaliar o material residual, casca de tungue (Aleurites fordii, Euphorbiaceae) compostado, para uso como substrato, no crescimento de mudas de alface, observou que as mudas apresentaram maior MSPA e MSSR quando se utilizou a casca de tungue pura, ou em mistura, em relação à utilização de substrato comercial como referência. $\mathrm{O}$ crescimento inferior, das mudas de alface, no substrato comercial, foi atribuído pelo autor à densidade elevada, menor espaço de aeração e reduzido teor de água disponível, deste material, em relação à casca de tungue.

Lima et al. (2007), ao avaliarem a mistura de resíduo da indústria de chá preto decomposto com vermiculita, no cultivo de mudas de alface e de tomate, também observaram valores, significativamente, mais elevados, de altura de planta e de matéria seca da parte aérea e da raiz, em comparação com o uso de vermiculita pura, o que atribuíram à melhor disponibilidade de nutrientes, resultante da decomposição do resíduo industrial. Daudt et al. (2007), ao investigarem a serragem de couro, pura, ou em mistura com casca de arroz carbonizada e vermiculita, como substrato para o cultivo de mudas de Tagetes patula L., observaram que a adição desse material reduziu a densidade, aumentou a porosidade e a água retida nas misturas, proporcionando boas condições físicas para o desenvolvimento das mudas. Entretanto, a elevada salinidade do material, mostrou ser limitante ao crescimento vegetal, reduzindo o comprimento das raízes e o desenvolvimento da parte aérea.

De maneira geral, observou-se que, com o cultivo em substrato à base de CFM compostada, pura, ou em mistura, foi possível alcançar elevados percentuais de germinação e de produção de mudas normais, com altura adequada ao transplantio, compatível com a idade da muda durante o período experimental e com o tamanho dos recipientes utilizados, de acordo com os padrões técnicos recomendados para mudas de tomate.

$\mathrm{O}$ uso da CFM in natura como substrato de enraizamento, nas três granulometrias, mostrou-se prejudicial para todas as características avaliadas, que diferiram, significativamente, dos demais tratamentos (Tabela 3).

Esses resultados podem estar relacionados com a alta CE encontrada no material in natura (Tabela 2), quando comparada com a do material compostado, nas três granulometrias, e com as suas características físicas inadequadas para uso como substrato, a saber, a porosidade total e o espaço de aeração inferiores aos ideais (Tabela 2), acarretando maior retenção de umidade no substrato, com formação de um filme d'água e redução da disponibi- 

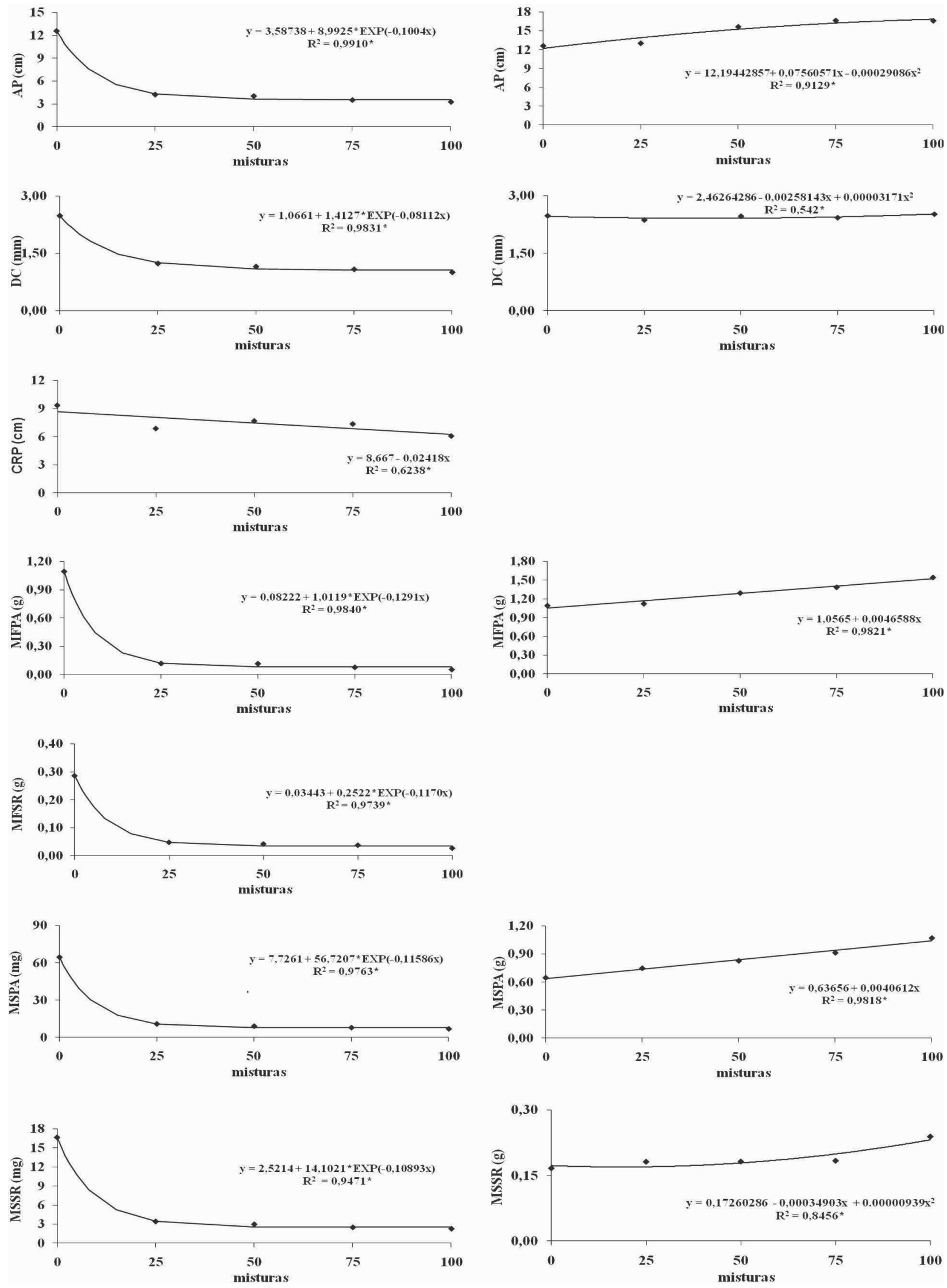

Figura 1. Altura de planta (AP), diâmetro de caule (DC) comprimento de raízes primárias (CRP), matéria fresca da parte aérea (MFPA), matéria fresca do sistema radicular (MFSR), matéria seca da parte aérea (MSPA) e matéria seca do sistema radicular (MSSR) de mudas de tomateiro, cultivadas em substrato CFM na granulometria $3 \mathrm{~mm}$ pura ou em mistura com o substrato comercial (SC) Plantmax ${ }^{\circledast}(0,25,50$, 75 e $100 \%)$, in natura (esquerda) e compostada (direita); $(* \mathrm{P}<0,05)$.

Rev. Ceres, Viçosa, v. 58, n.3, p. 350-358, mai/jun, 2011 
Tabela 3. Médias das características percentagem de estacas enraizadas (ENRZ), percentagem de estacas sobreviventes (ESBR), número de raízes primárias (NRP), comprimento de raízes primárias (CRP), massa de matéria fresca da parte aérea (MFPA), massa de matéria fresca do sistema radicular (MFSR), massa de matéria seca da parte aérea (MSPA) e massa de matéria seca do sistema radicular (MSSR) de estacas de Duranta repens, cultivadas em substrato de casca de fruto de mamoneira, pura, in natura e compostada, em três granulometrias

\begin{tabular}{lcccccccc}
\hline Tratamentos $^{1}$ & $\begin{array}{c}\text { ENRZ } \\
(\boldsymbol{\%})\end{array}$ & $\begin{array}{c}\text { ESBR } \\
(\boldsymbol{\%})\end{array}$ & NRP & $\begin{array}{c}\text { CRP } \\
(\mathbf{c m})\end{array}$ & $\begin{array}{c}\text { MFPA } \\
(\mathbf{g})\end{array}$ & $\begin{array}{c}\text { MFSR } \\
(\mathbf{g})\end{array}$ & $\begin{array}{c}\text { MSPA } \\
(\mathbf{g})\end{array}$ & $\begin{array}{c}\text { MSSR } \\
(\mathbf{g})\end{array}$ \\
\hline CFM 3 mm in & $1,56 \mathrm{~b}$ & $40,62 \mathrm{c}$ & $1,0 \mathrm{~b}$ & $0,75 \mathrm{~b}$ & $0,61 \mathrm{~d}$ & $0,01 \mathrm{c}$ & $0,16 \mathrm{c}$ & $0,002 \mathrm{~b}$ \\
CFM 3 mm dp & $76,56 \mathrm{a}$ & $100,00 \mathrm{a}$ & $9,0 \mathrm{a}$ & $3,98 \mathrm{a}$ & $1,44 \mathrm{a}$ & $0,27 \mathrm{a}$ & $0,38 \mathrm{ab}$ & $0,024 \mathrm{a}$ \\
CFM 5 mm in & $0,00 \mathrm{~b}$ & $75,00 \mathrm{~b}$ & $0,0 \mathrm{~b}$ & $0,00 \mathrm{~b}$ & $0,98 \mathrm{c}$ & $0,00 \mathrm{c}$ & $0,21 \mathrm{c}$ & $0,000 \mathrm{~b}$ \\
CFM 5 mm dp & $81,25 \mathrm{a}$ & $98,44 \mathrm{a}$ & $8,0 \mathrm{a}$ & $3,45 \mathrm{a}$ & $1,51 \mathrm{a}$ & $0,26 \mathrm{ab}$ & $0,38 \mathrm{ab}$ & $0,023 \mathrm{a}$ \\
CFM 10 mm in & $0,00 \mathrm{~b}$ & $90,62 \mathrm{~b}$ & $0,0 \mathrm{~b}$ & $0,00 \mathrm{~b}$ & $1,11 \mathrm{bc}$ & $0,00 \mathrm{c}$ & $0,32 \mathrm{~b}$ & $0,000 \mathrm{~b}$ \\
CFM 10 mm dp & $79,38 \mathrm{a}$ & $98,44 \mathrm{a}$ & $8,3 \mathrm{a}$ & $4,06 \mathrm{a}$ & $1,50 \mathrm{a}$ & $0,26 \mathrm{ab}$ & $0,39 \mathrm{a}$ & $0,023 \mathrm{a}$ \\
VM & $87,40 \mathrm{a}$ & $96,88 \mathrm{a}$ & $7,2 \mathrm{a}$ & $4,03 \mathrm{a}$ & $1,29 \mathrm{~b}$ & $0,19 \mathrm{~b}$ & $0,37 \mathrm{ab}$ & $0,021 \mathrm{a}$ \\
\hline Média geral & 45,59 & 85,71 & 4,8 & 2,32 & 1,21 & 0,14 & 0,31 & 0,013 \\
\hline
\end{tabular}

Médias seguidas da mesma letra minúscula nas colunas não diferem entre si pelo teste de Tukey a $5 \%$ de probabilidade. ${ }^{1} \mathrm{CFM}=$ casca de fruto da mamoneira; in = in natura; $\mathrm{dp}=$ compostada; $\mathrm{VM}=$ vermiculita.

lidade de oxigênio ao redor da base da estaca, prejudicando o processo de enraizamento.

Por outro lado, com a utilização da CFM compostada, não foram observados efeitos negativos em nenhuma das características avaliadas nas três granulometrias utilizadas (Tabela 3). Os valores de ENRZ, ESBR, NRP, CRP, MSPA e MSSR, nas três granulometrias, não diferiram, estatisticamente, entre si e do tratamento com vermiculita. A MFPA das mudas, provenientes do tratamento CFM compostada, nas três granulometrias utilizadas, foi significativamente superior à do tratamento que utilizou vermiculita como substrato. A MFSR das mudas produzidas na granulometria de $3 \mathrm{~mm}$ foi superior à MFSR obtida na vermiculita, não diferindo, significativamente, daquela das mudas produzidas nas demais granulometrias.

Os resultados deste trabalho concordam com os obtidos por Still et al. (1976) que também relataram o aumento do percentual de enraizamento de estacas de feijão mungo, em extratos de casca compostada de cinco diferentes espécies vegetais. Yates \& Rogers (1981) relataram o aumento significativo do peso de matéria seca de mudas de crisântemo relacionado com o aumento do período de compostagem da casca de pinus, usada como substrato. Gruszynski (2002), ao avaliar casca de tungue (Aleurites fordii, Euphorbiaceae) compostada, para uso como substrato no enraizamento de estacas e no desenvolvimento de plantas de crisântemo, não encontrou diferença significativa em relação à casca de arroz carbonizada, usada como substrato referencial, no percentual de enraizamento, no número de raízes, na massa de matéria fresca e massa de matéria seca do sistema radicular, massa de matéria fresca e seca da parte aérea, nem na altura de planta.

Os resultados favoráveis, obtidos com a CFM compostada para uso como substrato, podem estar associados às características do material, como a condutividade elétrica, a porosidade total e o espaço de aeração, nas três granulometrias estudadas, e demonstram a viabilidade de sua utilização como substrato, pura ou em mistura, para a germinação de sementes e enraizamento de estacas. Entretanto, são necessários experimentos adicionais mais detalhados, incluindo análises complementares, como, por exemplo, determinações do número de folhas, da área foliar, da relação massa seca de caule/massa seca foliar, da relação massa seca de parte aérea/massa seca de raiz, da coloração verde das folhas (índice SPAD), dos teores foliares de nutrientes, para que se possa concluir sobre a melhor composição da mistura a ser utilizada.

\section{CONCLUSÕES}

O processo de decomposição aeróbica melhorou as características químicas e físicas da CFM.

A CFM in natura é inadequada, pura ou em mistura, como substrato para a produção de mudas das espécies indicadoras utilizadas, a saber, tomateiro (Lycopesicon esculentum) e pingo-de-ouro (Duranta repens).

A CFM compostada pode ser utilizada, pura ou em mistura, na composição de substrato para a germinação de sementes e produção de mudas de tomateiro (Lycopesricon esculentum) e para o enraizamento de estacas de pingo-de-ouro (Duranta repens).

A CFM decomposta, nas granulometrias de 3 e $5 \mathrm{~mm}$, apresentou características físicas mais adequadas para uso como substrato.

\section{AGRADECIMENTOS}

Os autores agradecem ao Convênio MCT/SECTI/ FINEP/FAPERJ, $n^{\circ}$ 0.1.04.0821, e à FAPERJ processo $n^{\circ}$ E26/170.871/2005 pelo auxílio financeiro. 


\section{REFERÊNCIAS}

Abreu MF, Abreu CA \& Bataglia OC (2002) Uso da análise química na avaliação da qualidade de substratos e componentes. In: Furlani AMC, Bataglia OC, Abreu MF, Abreu CA, Furlani PR, Quaggio JA \& Minami K (Coords.). Caracterização, manejo e qualidade de substratos para produção de plantas. Documentos IAC, 70. Campinas, Instituto Agronômico, p.17-28.

Andriolo JL, Duarte TS, Ludke L \& Skrebsky EC (1999) Características de substratos para o cultivo do tomateiro fora do solo. Horticultura Brasileira, 17:215-219.

Carrijo OA, Liz RS \& Makishima N (2002) Fibra da casca do coco verde como substrato agrícola. Horticultura Brasileira, 20:533535

Cavins TJ, Whipker BE, Fonteno WC, Harden B, Mccall I \& Gibson JL (2000) Monitoring and managing pH and EC using the Pour Thru Extraction Method. North Carolina, NC State University. 17p. (Horticultural Information Leaflet 590).

Cruz CD (2006) Programa GENES: estatística experimental e matrizes. Viçosa, Ed. UFV. 285p.

Daudt RHS, Gruszynski C \& Kämpf AN (2007) Uso de resíduos de couro wet-blue como componente de substrato para plantas. Ciência Rural, 37:91-99.

De Boodt M \& Verdonck O (1972) The physical properties of the substrates in horticulturae. Acta Horticulturae, 26:37-44.

Estaún V, Calvet C, Pagés M \& Grases, J M (1985) Chemical determination of fatty acids, organic acids and phenols, during olive marc composting process. Acta Horticulturae, 172:263270 .

Fermino MH (2002) O uso da analise física na avaliação da qualidade de componentes e substratos. In: Furlani AMC, Bataglia OC, Abreu MF, Abreu CA, Furlani PR, Quaggio JA \& Minami K (Coords.). Caracterização, manejo e qualidade de substratos para produção de plantas. Documentos IAC, 70. Campinas, Instituto Agronômico, p.29-37.

Giacomini SJ, Aita C, Hübner AP, Lunkes A, Guidini E \& Amaral EB (2003) Liberação de fósforo e potássio durante a decomposição de resíduos culturais em plantio direto. Pesquisa Agropecuária Brasileira, 38:1097-1104.

Gruszynski, C (2002) Resíduo agro-industrial "casca de tungue" como componente de substrato para plantas. Tese de Mestrado. Porto Alegre, Universidade Federal do Rio Grande do Sul. 99 p.

Handreck KA (1993) Properties of coir dust, and its use in the formulation of soilless potting media. Communications in Soil Science and Plant Analysis, 24:349-363.

Hardy GESt.J \& Sivasithamparam K (1989) Microbial, chemical and physical changes during composting of a eucalyptus (Eucalyptus calophylla and Eucalyptus diversicolor) bark mix. Biology and Fertility of Soils, 8:260-270.

Hartmann HT, Kester DE, Davies Jr FT \& Geneve RL (1997) Plant Propagation: Principles and Practices. $6^{\text {th }}$ ed. Upper Saddle River, Prentice Hall, (N. Jersey, USA), 770p.

Jasmim JM, Toledo RRV, Carneiro LA \& Mansur E (2006) Fibra de coco e adubação foliar no crescimento e na nutrição de Cryptanthus sinuosus. Horticultura Brasileira, 24:309-314.

Kämpf AN (2000a) Produção comercial de plantas ornamentais. Guaíba, Agropecuária, 254p.

Kämpf AN (2000b) Seleção de materiais para uso como substrato. In: Kämpf AN, Fermino MN Substrato para plantas: a base da produção vegetal em recipientes. Porto Alegre, Gênesis. p.139145 .
Kiehl EJ (1985) Fertilizantes orgânicos. São Paulo, Editora Ceres, 492 p.

Lacerda MRB, Passos MAA, Rodrigues JJV \& Barreto LP (2006) Características físicas e químicas de substratos a base de pó de coco e resíduo de sisal para produção de mudas de sabiá (Mimosa caesalpiniaefolia Benth). Revista Árvore, 30:163-170.

Lima JD, Moraes WS, Mendonça JC \& Nomura ES (2007) Resíduos da agroindústria de chá preto como substrato para produção de mudas de hortaliças. Ciência Rural, 37:1609-1613.

Lima RLS, Severino LS, Albuquerque RC, Beltrão NEM \& Sampaio LR (2008) Casca e torta de mamona avaliados em vasos como fertilizantes orgânicos. Revista Caatinga, 21:102-106.

Ortega MC, Moreno MT, Ordovas J \& Aguado MT (1996) Behaviour of different horticultural species in phytotoxicity bioassays of bark substrates. Scientia Horticulturae, 66:125132 .

Rosolem CA (2006) Potássio no solo em consequência da adubação sobre a palha de milheto e chuva simulada. Pesquisa Agropecuária Brasileira, 41:1033-1040.

Schmitz JAK, Souza PVD \& Kämpf NA (2002) Propriedades químicas e físicas de substratos de origem mineral e orgânica para o cultivo de mudas de recipiente. Ciência Rural, 32:937-944.

Severino LS, Moraes CRA, Gondim TMS, Cardoso GD \& Santos JW (2005) Fatores de conversão do peso de cachos e frutos para peso de sementes de mamona. Campina Grande, Embrapa Algodão, 15p. (Boletim de Pesquisa e Desenvolvimento, 56).

Still SM, Dirr MA \& Gartner JB (1976) Phytotoxic effects of several bark extracts on Mung bean and Cucumber growth. Journal of the American Society for Horticultural Science, 101:34-37.

Yates NL \& Rogers MN (1981) Effect of time, temperature, and nitrogen source on the composting of hardwood bark for use as a plant growing medium. Journal of the American Society for Horticultural Science, 106:589-593. 